\title{
Pulmonary Arterial Pressure at High Pulmonary Flow*
}

\author{
Noble O. Fowler † and John C. Holmes \\ (From the Cardiac Research Laboratory, Division of Cardiology, Department of Internal Medi- \\ cine, University of Cincinnati College of Medicine, and the Cincinnati General Hospital,
} Cincinnati, Ohio)

The relationship between pulmonary arterial pressure and pulmonary blood flow has been studied by a number of investigators in anesthetized animals (1), in man after pneumonectomy or unilateral pulmonary arterial occlusion $(2,3)$, and in normal man during exercise (4-7). With a few exceptions (1) these studies have agreed that doubling or trebling the pulmonary arterial flow does not produce a comparable increase of pulmonary arterial pressure. Sloan, Morris, Figley, and Lee (2) and Brofman (3) found in human subjects only a very slight rise of pulmonary arterial pressure during balloon occlusion of one main pulmonary artery branch when cardiovascular dynamics were normal. However, the relationship between pulmonary arterial pressure and pulmonary arterial blood flow at higher rates of flow has been examined by only a few investigators.

In 1950, Cournand, Riley, Himmelstein, and Austrian (8) published studies of pulmonary blood pressure in normal physicians at rest and during exercise and in patients who had had a pneumonectomy with a normal remaining lung. These investigators concluded that pulmonary blood flow in man can increase to approximately three times the normal before the pulmonary arterial pressure will rise above normal limits. Lategola studied pulmonary pressure and flow relationships at high flow levels achieved by occluding $50 \%$ or more of the pulmonary circulation in anesthetized dogs (9). Lategola also found that when pulmonary blood flow was increased to approximately 250 to $300 \%$ above normal, the pressure rose sharply.

\footnotetext{
* Submitted for publication March 15, 1965; accepted September 16, 1965.

Supported by U. S. Public Health Service grants HE06307 and HE-5445.

$\dagger$ Address requests for reprints to Dr. Noble $O$. Fowler, Cardiac Research Laboratory H-3, Cincinnati General Hospital, Cincinnati, Ohio 45229.
}

Unlike Cournand, he found some increment of pulmonary arterial pressure even when pulmonary blood flow was increased less than $100 \%$ above the normal.

In the foregoing studies of high pulmonary blood flow, the methods used for measuring pulmonary blood flow were necessarily indirect, and left atrial pressure was not measured. Thus the effect of pulmonary blood flow upon pulmonary vascular resistance could not be accurately computed. The purpose of the present study is to examine in anesthetized dogs the effect of increase of pulmonary blood flow under circumstances that permitted direct measurement of pulmonary blood flow and left atrial pressure. The pulmonary blood flows were measured at levels from $50 \%$ to $500 \%$ of normal,' and left atrial pressures were held constant in some experiments.

\section{Methods}

The experiments were performed upon 19 mongrel dogs that were in three groups.

Group 1 consisted of nine dogs. The experimental design for equal perfusion of the systemic and pulmonary circulations with a roller pump is described in detail elsewhere (10) and is only summarized here. Three animals were anesthetized with pentobarbital sodium, $30 \mathrm{mg}$ per $\mathrm{kg}$, intravenously. Six received morphine suiffate, $5 \mathrm{mg}$ per $\mathrm{kg}$, intramuscularly followed by intravenous chloralose in amounts required to maintain anesthesia. The animals received heparin, $5 \mathrm{mg}$ per $\mathrm{kg}$, intravenously. After opening the chest, ventilation with $100 \%$ oxygen was maintained at a constant level by means of a Harvard respirator set at 16 strokes per minute with a stroke volume of 250 to $300 \mathrm{ml}$. The pulmonary circulation was perfused through a cannula inserted through the proximal inferior vena cava into the arrested heart from a reservoir, which received the venous return from the distal superior and inferior venae cavae. The systemic circulation was perfused by means of cannulae inserted into the common carotid and proximal left subclavian arteries. The coronary arteries and right subclavian artery were excluded from the circulation. Pulmonary venous return was collected from a cannula inserted into the apex of the left ventricle and 
drained into a reservoir for pumping to the systemic circulation. Pulmonary and systemic flows were measured by simultaneous collection of the venous return from the left ventricle and venae cavae, respectively, into graduate cylinders. The dead space of the reservoirs and tubing was filled with pooled donor blood, which in most experiments was supplemented by $6 \%$ iso-oncotic dextran in saline with calcium, magnesium, and potassium chloride added to achieve physiologic concentrations.

Blood temperature was monitored constantly and was maintained at $37.5 \pm 0.5^{\circ} \mathrm{C}$. Blood $\mathrm{pH}$ was measured at $37^{\circ} \mathrm{C}$ by a Beckman expanded scale $\mathrm{pH}$ meter after each change in flow setting. One hundred to two hundred $\mathrm{ml}$ $2.5 \% \mathrm{NaHCO}_{3}$ was added to the blood at $15-$ to 30 -minute intervals when necessary. Blood oxygen saturations were determined in the Van Slyke manometric apparatus. Pressures in the pulmonary artery, left atrium, and aorta were determined simultaneously through Cournand catheters with Statham transducers and a four channel direct-writing Sanborn Polyviso electrocardiograph.

Systemic and pulmonary blood flows were always equal. A flow of $100 \mathrm{ml}$ per $\mathrm{kg}$ per minute was considered to be normal. Pressures were evaluated in each experiment at flow levels of approximately 50,100,200,300, 400, and $500 \mathrm{ml}$ per $\mathrm{kg}$ per minute. Thus, blood flow rates up to $500 \%$ of normal could be achieved. Since the maximal capacity of the pump was $3,600 \mathrm{ml}$ per minute, it was riecessary to obstruct the blood flow to one lung in order to achieve pulmonary flows above 250 to $300 \%$ of normal. This was achieved in eight animals. In four dogs a balloon was inflated in the left main branch of the pulmonary artery. The proper placement of the balloon was verified by palpation and at autopsy. A snare intermittently occluded the right pulmonary artery main branch in two dogs and the left in one. The right pulmonary artery was ligated in one dog, 335. Equal perfusion of the two lungs was assumed, and the measured blood flow through one lung was doubled in order to give the equivalent flow through both lungs. Hence, a pulmonary flow of $50 \mathrm{ml}$ per $\mathrm{kg}$ per minute through one lung was considered normal. In all balloon or snare occlusion experiments, pressure values for pulmonary flow between 50 and $250 \mathrm{ml}$ per $\mathrm{kg}$ per minute were determined in two ways, with perfusion of both lungs and of one lung only. The values were plotted graphically, and the experimental results were accepted only if the pressure values obtained by the two methods agreed by falling on the same curve. Pulmonary flows above $250 \%$ of normal were usually achieved by perfusion of one lung only. Pressure values were measured at a given flow setting only after the lapse of 1 to 2 minutes to assure stability. No dextran or fresh donor blood was added to the reservoirs once the experiment had begun. Carotid sinus reflexes were evaluated, and hematocrits were measured at the end of each experiment.

In group 2, six additional animals were prepared as were those of group 1, with the following exceptions. To avoid the effect of viscosity reduction upon the pressure/flow curve of the pulmonary artery, no dextran was added to the donor blood. All experiments were carried out with the right pulmonary artery ligated, and a blood flow of $50 \mathrm{ml}$ per $\mathrm{kg}$ per minute through the left lung was considered normal. Pulmonary arterial pressures were evaluated at flow levels of from 50 to $500 \%$ of normal. Left atrial pressure was maintained constant at $10 \mathrm{~mm}$ $\mathrm{Hg}$ in each of the six animals by adjusting the left atrial reservoir. In addition, pressure/flow curves were evaluated in four of the six animals while the left atrial pressure was held constant at $5 \mathrm{~mm} \mathrm{Hg}$. In these experiments, blood $\mathrm{pH}$ was controlled between 7.35 and 7.45.

In group 3, to duplicate more closely the experiments of Lategola (9), six additional animals were studied during left lower lobe perfusion. Constant return to the right atrium was maintained as described earlier, but the blood was first pumped through a disposable plastic oxygenator bag ${ }^{1}$ to provide adequate gas exchange. The heart was permitted to beat, but its output was controlled by the roller pump, which regulated flow to the right atrium. Pulmonary blood flows were estimated from the systemic venous return via the venae cavae and hence were consistently lower than the actual flow because of loss through the coronary circulation. Blood flow was set at $100 \mathrm{ml}$ per $\mathrm{kg}$ per minute, which was considered normal. At this flow level, measurements of hematocrit, blood $\mathrm{pH}$, systemic arterial oxygen saturation, and pulmonary arterial and left atrial pressure were made. Then the right main pulmonary artery and the branch arteries to the left upper and middle lobes were ligated. In four of the six animals, pulmonary flow was reduced until the pulmonary arterial-left atrial pressure difference was the same as when all lobes were perfused with blood at a flow of $100 \mathrm{ml}$ per $\mathrm{kg}$ per minute. This new flow was considered to represent normal flow to the left lower lobe. The flow was then increased in steps to a maximum of $400 \%$ of normal or until the left heart began to fail. Measures of left atrial and pulmonary arterial pressure were repeated at each level of blood flow. Blood $\mathrm{pH}$, hematocrit, and systemic arterial oxygen saturation were repeated at the end of the experiments. In two of the six animals, 347 and 350, while the left lower lobe was perfused at $75 \mathrm{ml}$ per $\mathrm{kg}$ per minute, the oxygenator bag was disconnected. Then, while the lungs were ventilated with $100 \%$ oxygen, serial blood samples were analyzed for $\mathrm{pH}, \mathrm{CO}_{2}$ content, and systemic arterial saturation for a period of 9 minutes. Pulmonary arterial pressure/flow curves were not evaluated in these two animals.

\section{Results}

The results of these experiments are summarized in Tables I to IV. In animals of group 1, with both lungs perfused, initial mean pulmonary arterial pressures were from 13 to $23.6 \mathrm{~mm} \mathrm{Hg}$ at $100 \mathrm{ml}$ per $\mathrm{kg}$ per minute flow (Table I). These were considered to be control pressures. These

1 Pulmo-Pak disposable bubble oxygenator, Abbott Laboratories, North Chicago, Ill. 


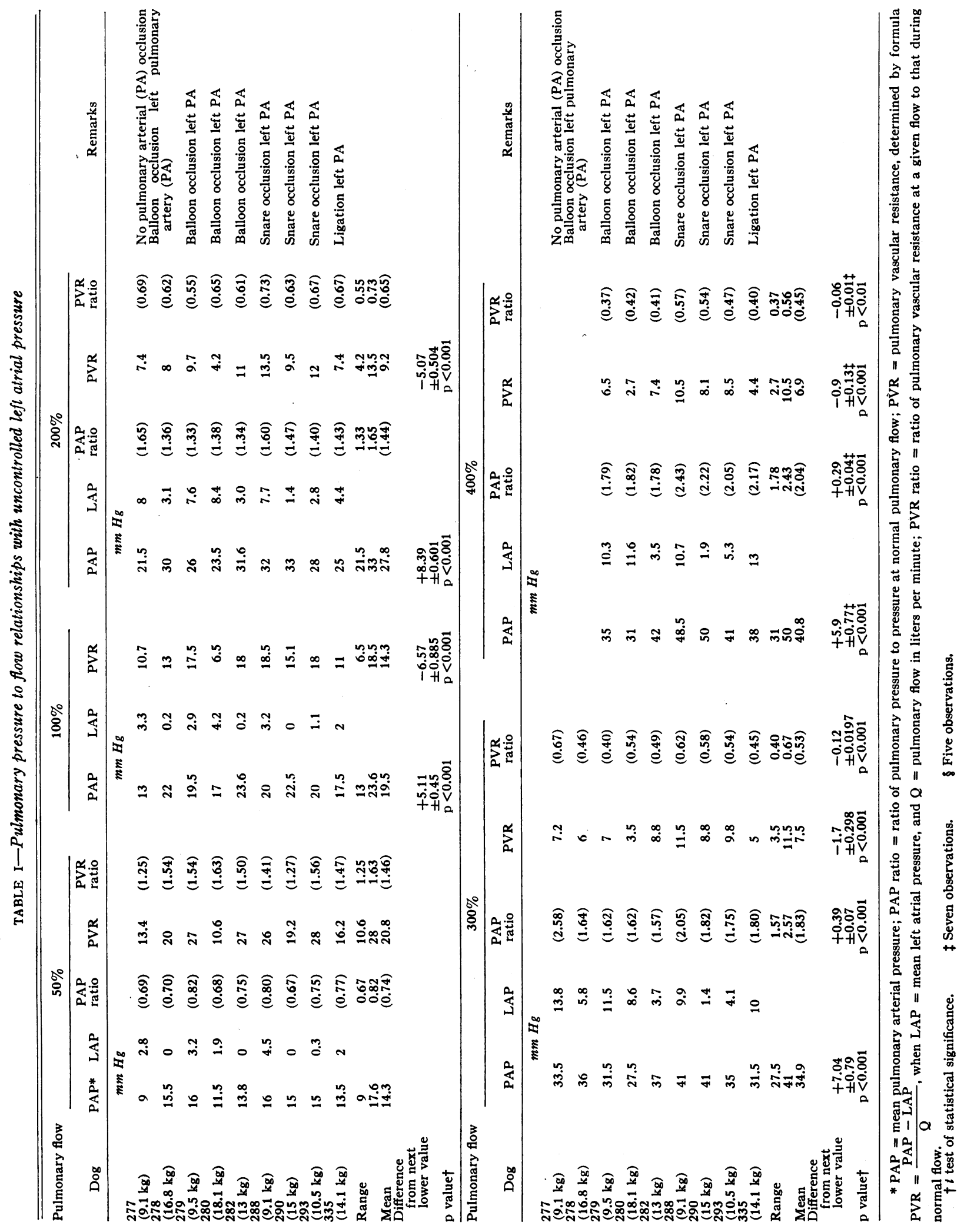




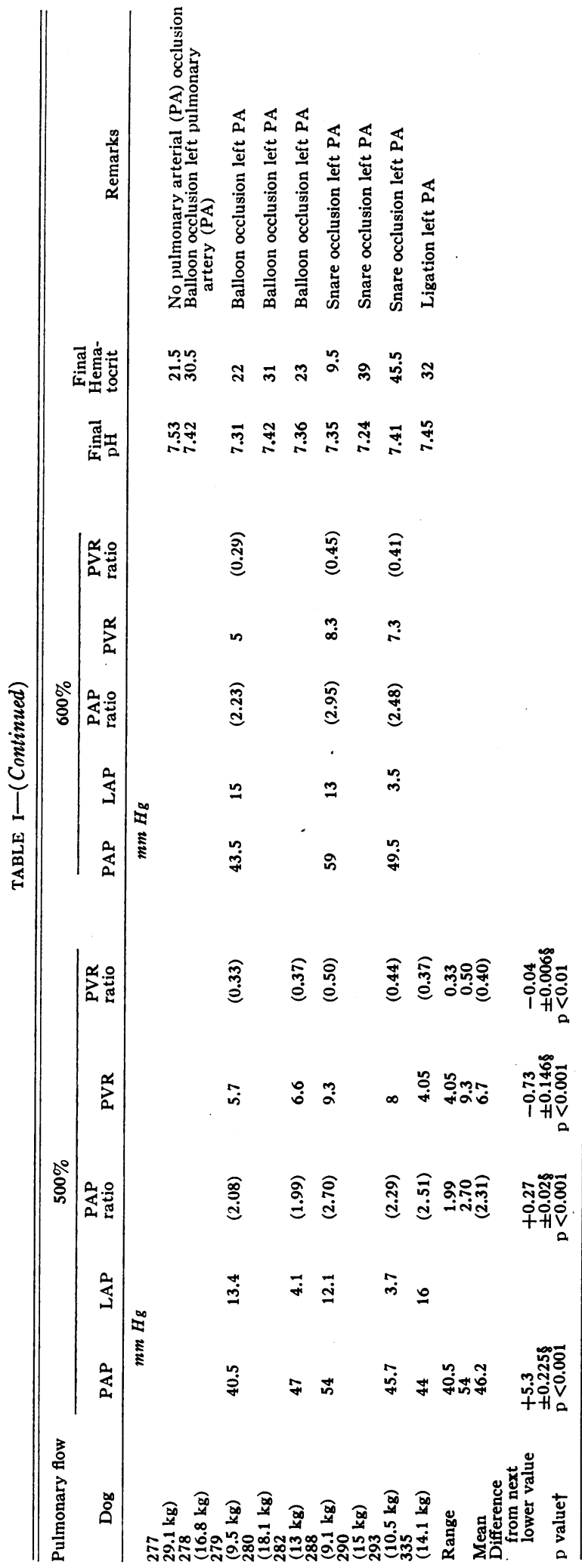

pressures averaged several millimeters $\mathrm{Hg}$ higher than in closed-chest animals because of the loss of negative intrathoracic pressure and the positive pressure used in ventilation. The changes in pulmonary arterial pressure and pulmonary vascular resistance when the flow was decreased to $50 \%$ of normal and increased to $200,300,400,500$, and $600 \%$ of normal are shown in Table I. In all instances the pulmonary vascular resistance rose as the pulmonary arterial flow was decreased and fell significantly as the pulmonary arterial flow was increased. When pulmonary arterial flow was doubled, the mean ratio of pressure to the control was 1.44 , Table I. When it was trebled, the mean ratio of pressure to the control was 1.83 , and when it was quadrupled the pressure increased just a little over twice the control to 2.04 . In a number of these animals the final hematocrit was quite low because considerable dextran had to be added to the donor blood to have sufficient volume for the experiments. However, in two animals, 290 and 293, the hematocrits were normal at 39 and 45.5 . Blood $\mathrm{pH}$ was well controlled except that in animal 290 the final $\mathrm{pH}$ was 7.24. Left atrial pressure remained within normal limits, that is, below $12.5 \mathrm{~mm} \mathrm{Hg}$, in six animals but rose above this level in three. The values for left atrial pressure shown in Table I do not always rise with increasing pulmonary blood flow. The reason for this is that in some experiments, the tabulated values for lower flows were obtained with both lungs perfused, whereas in all experiments, values for higher flows were obtained with only one lung perfused. Left atrial pressure in these experiments varied with actual flow rather than percentage flow, and it would be higher if normal flow were obtained by $100 \mathrm{ml}$ per kg per minute flow through both lungs than if obtained by $50 \mathrm{ml}$ per $\mathrm{kg}$ per minute through one lung.

Similar results were observed in the animals of group 2 with constant left atrial pressure (Table II). When left atrial pressure was held constant at $10 \mathrm{~mm} \mathrm{Hg}$ and pulmonary flow was doubled, the ratio of pulmonary arterial pressure to control was 1.28. When flow was trebled, the pressure ratio to control was 1.53 , and when flow was quadrupled, pressure ratio to control was 1.78 . Pulmonary vascular resistance fell significantly as flow was increased to $300 \%$, but it did not fall sig- 
TABLE II

Pulmonary pressure to flow relationships

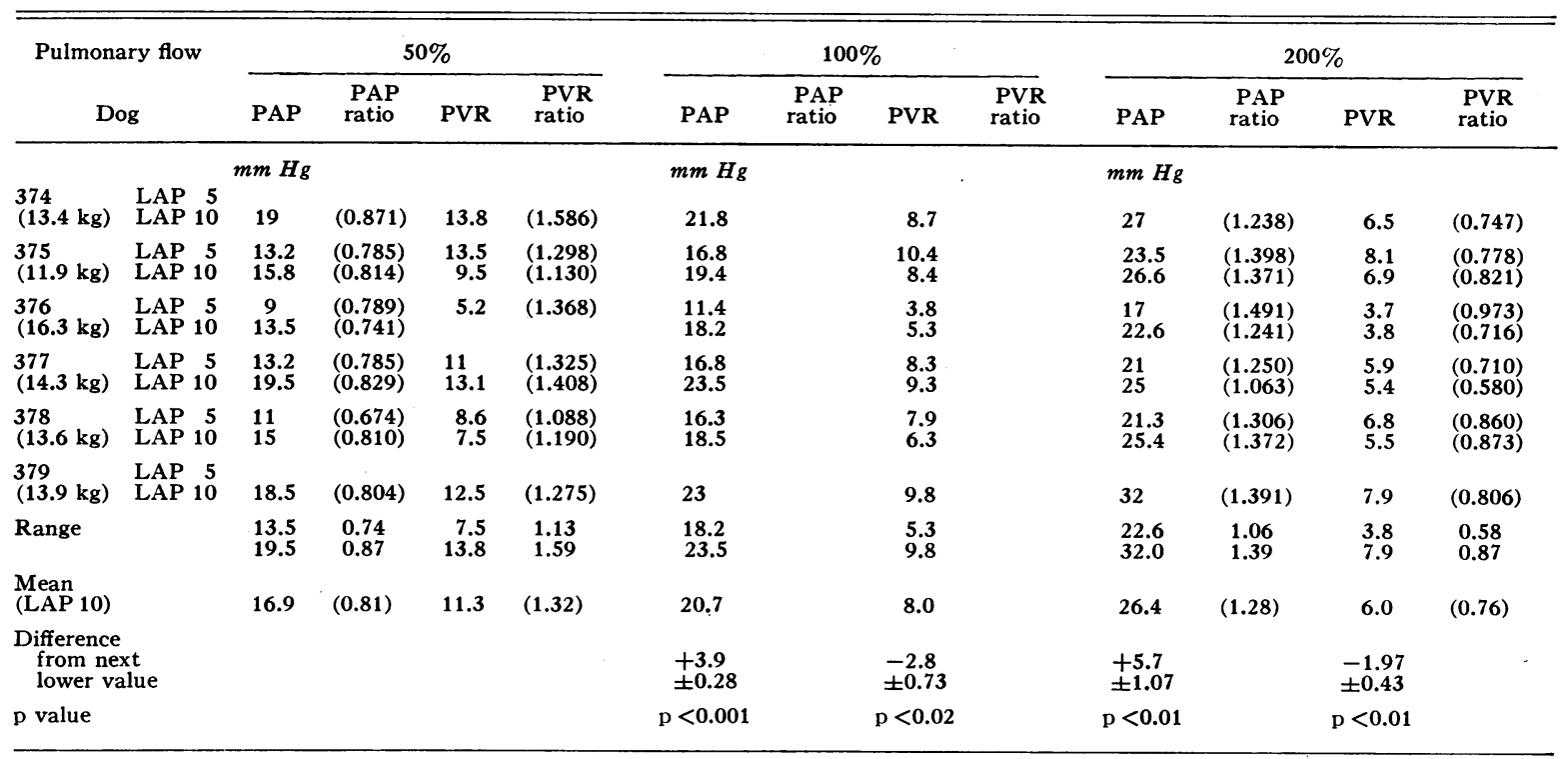

nificantly at $400 \%$ and $500 \%$. Figures 1 and 2 show the effects of increase in pulmonary blood flow upon the pulmonary arterial-left atrial pressure gradient and pulmonary vascular resistance in dog 282. In no instance was there a sharp break upward in the pulmonary arterial-left atrial pressure gradient as the flow reached 350 to $400 \%$ of normal that would correspond to the area of sharp upward increase of pulmonary arterial pressure found by Lategola (9). Likewise, the pulmonary vascular resistance continued to decrease as the

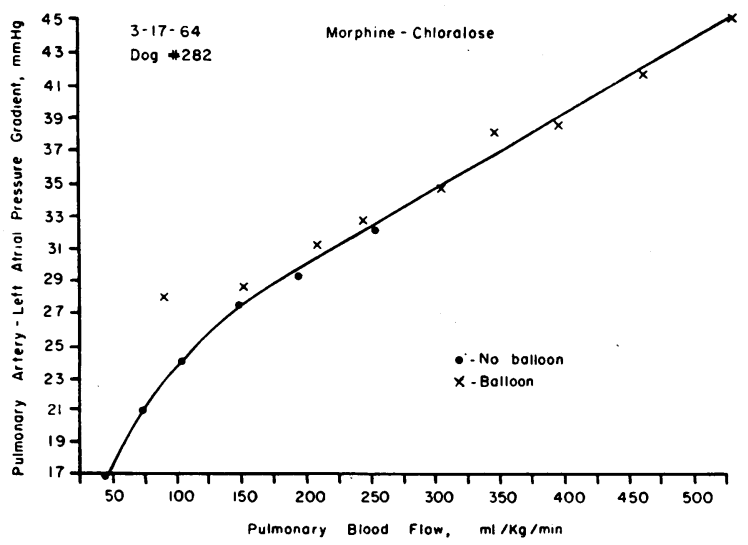

Fig. 1. Relationship betweEn PULmonary arterialLEFT ATRIAL PRESSURE GRADIENT AND PULMONARY BLOOD FLOW IN ONE EXPERIMENT. Left atrial pressure is not constant. flow was increased. At no point did it rise. The values obtained by balloon occlusion of the left pulmonary artery, as indicated by the X's, were comparable to those obtained without balloon occlusion at flows up to $250 \%$ of normal. The linearity of the pressure/flow curve in Figure 1 above $200 \mathrm{ml}$ per $\mathrm{kg}$ per minute flow is consistent with the configuration usually observed in a passive vascular system (11). Figures 3 and 4 show the results obtained in $\operatorname{dog} 378$ with left atrial pressure held constant. The relation of pressure to flow is essentially linear over the range investigated. In one experiment, to study reproducibility, pulmonary blood flow was at first set at a

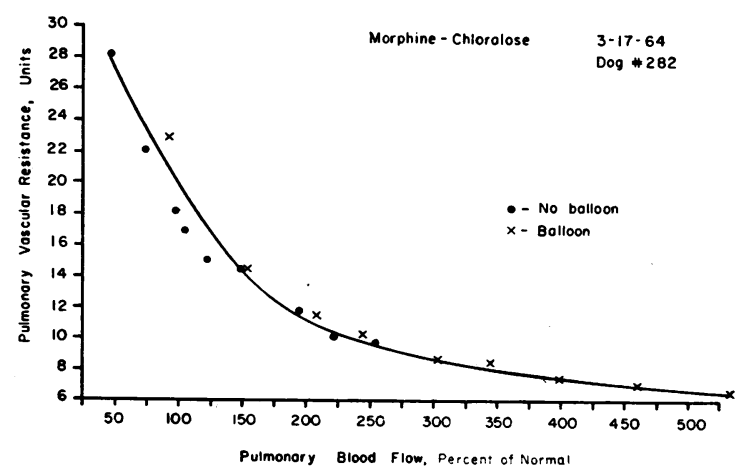

Fig. 2. Relationship betweEN PUlmonary vascular RESISTANCE AND PULMONARY - BLOOD FLOW IN THE SAME ANIMAL AS IN Figure 1. 
TABLE II

with constant left atrial pressure

\begin{tabular}{|c|c|c|c|c|c|c|c|c|c|c|c|c|}
\hline \multicolumn{4}{|c|}{$300 \%$} & \multicolumn{4}{|c|}{$400 \%$} & \multicolumn{4}{|c|}{$500 \%$} & \multirow[b]{2}{*}{$\begin{array}{l}\text { Hema- } \\
\text { tocrit }\end{array}$} \\
\hline PAP & $\begin{array}{l}\text { PAP } \\
\text { ratio }\end{array}$ & PVR & $\begin{array}{l}\text { PVR } \\
\text { ratio }\end{array}$ & PAP & $\begin{array}{l}\text { PAP } \\
\text { ratio }\end{array}$ & PVR & $\begin{array}{l}\text { PVR } \\
\text { ratio }\end{array}$ & PAP & $\begin{array}{l}\text { PAP } \\
\text { ratio }\end{array}$ & PVR & $\begin{array}{l}\text { PVR } \\
\text { ratio }\end{array}$ & \\
\hline$m m \mathrm{Hg}$ & & & & $m m \mathrm{Hg}$ & & & & $m m \mathbf{H g}$ & & & & \\
\hline 32.5 & $(1.490)$ & 5.6 & $(0.643)$ & 38 & (1.743) & 5.4 & $(0.620)$ & 45 & $(2.064)$ & 5.2 & $(0.597)$ & 50 \\
\hline $\begin{array}{l}30 \\
30.7\end{array}$ & $\begin{array}{l}(1.785) \\
(1.582)\end{array}$ & $\begin{array}{l}7.0 \\
6.5\end{array}$ & $\begin{array}{l}(0.673) \\
(0.773)\end{array}$ & $\begin{array}{l}34.7 \\
34.8\end{array}$ & $\begin{array}{l}(2.065) \\
(1.793)\end{array}$ & $\begin{array}{l}6.7 \\
5.2\end{array}$ & $\begin{array}{l}(0.644) \\
(0.619)\end{array}$ & $\begin{array}{l}37 \\
38\end{array}$ & $\begin{array}{l}(2.202) \\
(1.958)\end{array}$ & $\begin{array}{l}5.4 \\
4.6\end{array}$ & $\begin{array}{l}(0.519) \\
(0.547)\end{array}$ & 45 \\
\hline $\begin{array}{l}22.5 \\
27.4\end{array}$ & $\begin{array}{l}(1.973) \\
(1.505)\end{array}$ & $\begin{array}{l}3.7 \\
\mathbf{3 . 4}\end{array}$ & $\begin{array}{l}(0.973) \\
(0.641)\end{array}$ & $\begin{array}{l}28 \\
32.2\end{array}$ & $\begin{array}{l}(2.456) \\
(1.769)\end{array}$ & $\begin{array}{l}3.6 \\
3.3\end{array}$ & $\begin{array}{l}(0.947) \\
(0.622)\end{array}$ & $\begin{array}{l}34 \\
37\end{array}$ & $\begin{array}{l}(2.982) \\
(2.032)\end{array}$ & $\begin{array}{l}3.6 \\
3.3\end{array}$ & $\begin{array}{l}(0.947) \\
(0.622)\end{array}$ & 39 \\
\hline $\begin{array}{l}25.3 \\
29\end{array}$ & $\begin{array}{l}(1.505) \\
(1.234)\end{array}$ & $\begin{array}{l}4.8 \\
4.4\end{array}$ & $\begin{array}{l}(0.578) \\
(0.473)\end{array}$ & $\begin{array}{l}30 \\
33\end{array}$ & $\begin{array}{l}(1.785) \\
(1.404)\end{array}$ & $\begin{array}{l}4.2 \\
3.9\end{array}$ & $\begin{array}{l}(0.506) \\
(0.419)\end{array}$ & $\begin{array}{l}34.5 \\
37.3\end{array}$ & $\begin{array}{l}(2.053) \\
(1.587)\end{array}$ & $\begin{array}{l}4.2 \\
3.8\end{array}$ & $\begin{array}{l}(0.506) \\
(0.408)\end{array}$ & 38 \\
\hline $\begin{array}{l}27.2 \\
32\end{array}$ & $\begin{array}{l}(1.668) \\
(1.729)\end{array}$ & $\begin{array}{l}5.5 \\
5.4\end{array}$ & $\begin{array}{l}(0.696) \\
(0.857)\end{array}$ & $\begin{array}{l}36.8 \\
39\end{array}$ & $\begin{array}{l}(2.257) \\
(2.108)\end{array}$ & $\begin{array}{l}5.5 \\
5.4\end{array}$ & $\begin{array}{l}(0.696) \\
(0.857)\end{array}$ & $\begin{array}{l}42 \\
45.8\end{array}$ & $\begin{array}{l}(2.576) \\
(2.475)\end{array}$ & $\begin{array}{l}5.5 \\
5.4\end{array}$ & $\begin{array}{l}(0.696) \\
(0.857)\end{array}$ & 43 \\
\hline 37.8 & $(1.643)$ & 6.5 & $(0.663)$ & 43.5 & (1.891) & 5.7 & $(0.581)$ & 49.5 & $(2.152)$ & 5.7 & $(0.581)$ & 47 \\
\hline $\begin{array}{l}27.4 \\
37.8\end{array}$ & $\begin{array}{l}1.23 \\
1.73\end{array}$ & $\begin{array}{l}3.4 \\
6.5\end{array}$ & $\begin{array}{l}0.47 \\
0.86\end{array}$ & $\begin{array}{l}32.2 \\
43.5\end{array}$ & $\begin{array}{l}1.40 \\
2.11\end{array}$ & $\begin{array}{l}3.3 \\
5.7\end{array}$ & $\begin{array}{l}0.42 \\
0.86\end{array}$ & $\begin{array}{l}37 \\
49.5\end{array}$ & $\begin{array}{l}1.59 \\
2.58\end{array}$ & $\begin{array}{l}3.3 \\
5.7\end{array}$ & $\begin{array}{l}0.41 \\
0.86\end{array}$ & \\
\hline 31.6 & (1.53) & 5.3 & $(0.68)$ & 36.8 & (1.78) & 4.8 & $(0.62)$ & 42.1 & $(2.04)$ & 4.7 & $(0.60)$ & \\
\hline $\begin{array}{l}+5.1 \\
\pm 0.42\end{array}$ & & $\begin{array}{l}-0.7 \\
\pm 0.06\end{array}$ & & $\begin{array}{l}+5.2 \\
\pm 0.45\end{array}$ & & $\begin{array}{l}-0.48 \\
\pm 0.20\end{array}$ & & $\begin{array}{l}+5.4 \\
\pm 0.61\end{array}$ & & $\begin{array}{l}-0.17 \\
\pm 0.10\end{array}$ & & \\
\hline$p<0.001$ & - & $\mathrm{p}<0.001$ & & $\mathrm{p}<0.001$ & & $\mathrm{p}<0.05$ & & $\mathrm{p}<0.001$ & & $\mathrm{p}>0.1$ & & . \\
\hline
\end{tabular}

very low level, $16 \%$ of normal, and then it was increased stepwise to $360 \%$ of normal and decreased in like manner. It may be seen that the curves are very slightly different but follow the same slopes (Figure 5). Figure 6 is a graph relating the changes in pulmonary vascular resistance in all animals of group 2 to the changes of pulmonary blood flow. Mean values and the ranges are shown. Again, there is a continuing decline in pulmonary vascular resistance as pulmonary blood flow is increased. Figure 7 compares the pulmonary pressure to flow relationship obtained in the experiments of Cournand and coworkers (8), Brofman and co-workers (12), and

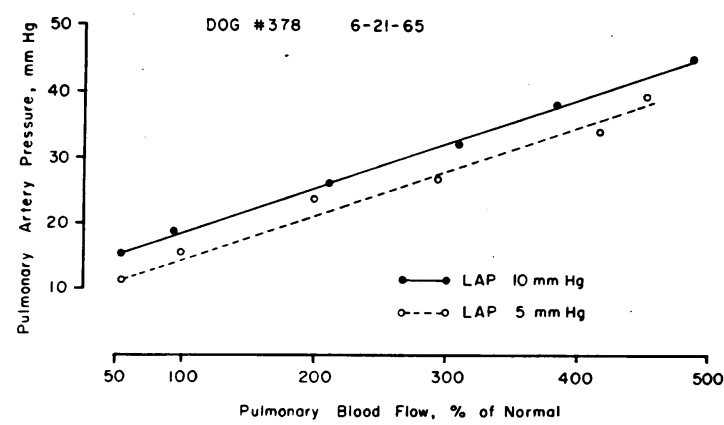

Fig. 3. RELATIONSHIP BETWEEN PULMONARY ARTERIAL PRESSURE AND PULMONARY BLOOD FLOW. Upper curve, left atrial pressure (LAP) is constant at $10 \mathrm{~mm} \mathrm{Hg}$; lower curve, left atrial pressure is constant at $5 \mathrm{~mm} \mathrm{Hg}$.
Lategola (9) with those obtained in the present studies with left atrial pressure held constant at $10 \mathrm{~mm} \mathrm{Hg}$. At pulmonary blood flows of 250 to $300 \%$ above normal, our curve does not show the sharp upward increment of pressure demonstrated by the Cournand and Lategola curves. The curve obtained in our studies has a slope very similar to that obtained by Brofman in man while employing exercise and balloon occlusion of one pulmonary artery (12).

The results obtained in four animals of group 3 during left lower lobe perfusion are presented in Table III and Figure 8. In these animals, the increment of pulmonary arterial pressure at a given flow increment was somewhat greater than

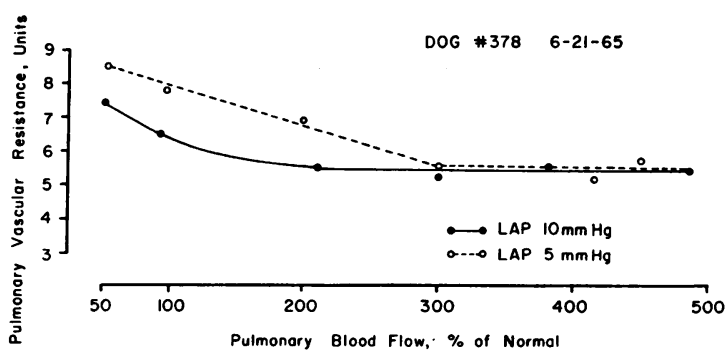

Fig. 4. RELATIONShip BETWEen PULMONARY VASCUlak RESISTANCE AND PULMONARY BLOOD FLOW. The animal is the same as in Figure 3. Upper curve, left atrial pressure is constant at $5 \mathrm{~mm} \mathrm{Hg}$; lower curve, left atrial pressure is constant at $10 \mathrm{~mm} \mathrm{Hg}$. 
TABLE III

Pressure to flow relationships

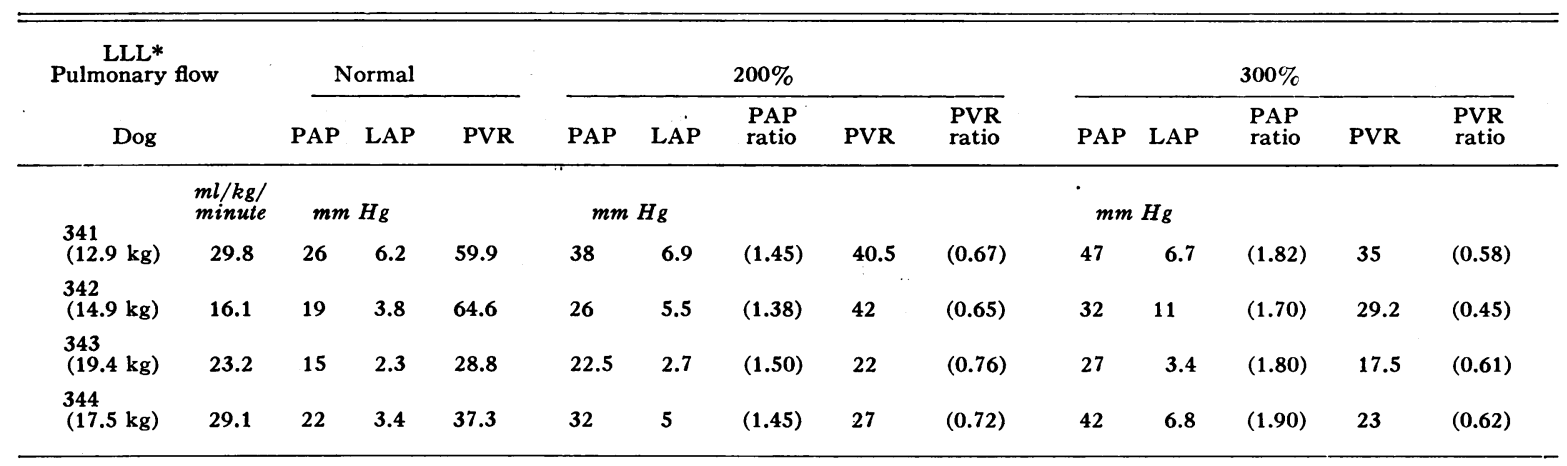

* LLL $=$ left lower lobe.

$+\mathrm{SaO}_{2}=$ systemic arterial oxygen saturation. $\$ 345 \%$.

in group 1. In two of these animals, 342 and 344, pulmonary vascular resistance did not fall as flow was increased above $300 \%$. However, in no animal was there an increase of pulmonary vascular resistance with increasing flow (Figure 8 ). In three animals of this group, arterial oxygen saturations were maintained at $100 \%$ of capacity or above. In one animal, 343 , the systemic arterial oxygen saturation was $88.6 \%$ at the termination of the study. In animals 347 and 350, when the bag oxygenator was removed from the blood flow line, there was evidence of inadequate pulmonary gas diffusion despite positive pressure ventilation

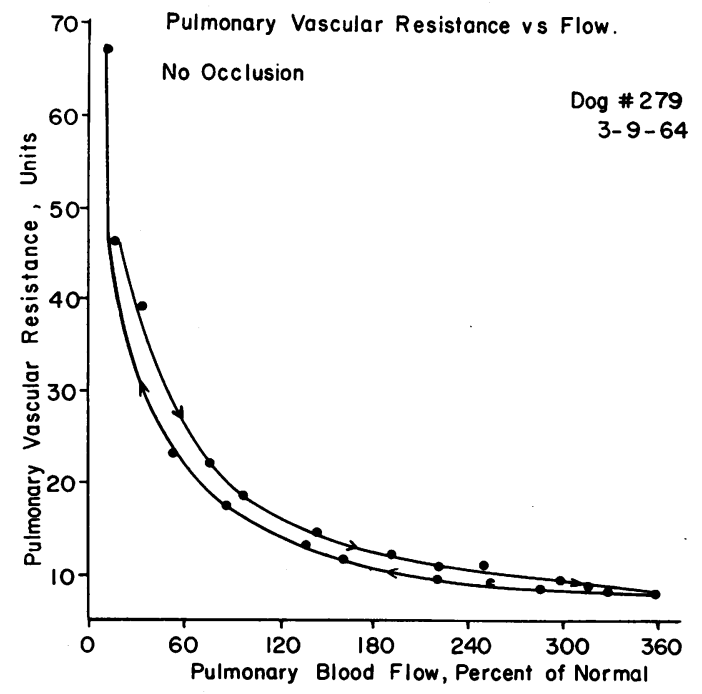

Fig. 5. Relationship between pUlmonary vascular RESISTANCE AND PULMONARY BLOOD FLOW TO SHOW REPRODUCIBILITY OF DATA AND ABSENCE OF HYSTERESIS. Left atrial pressure is not controlled. with $100 \%$ oxygen (Table IV). In these two animals, arterial oxygen saturation fell from normal to $64.7 \%$ in one and to $26.5 \%$ in the other within 9 minutes.

\section{Discussion}

The pressure/flow curves and the relationship between pulmonary vascular resistance and flow found in these experiments are similar to those shown by Williams (13) in the perfused left lower

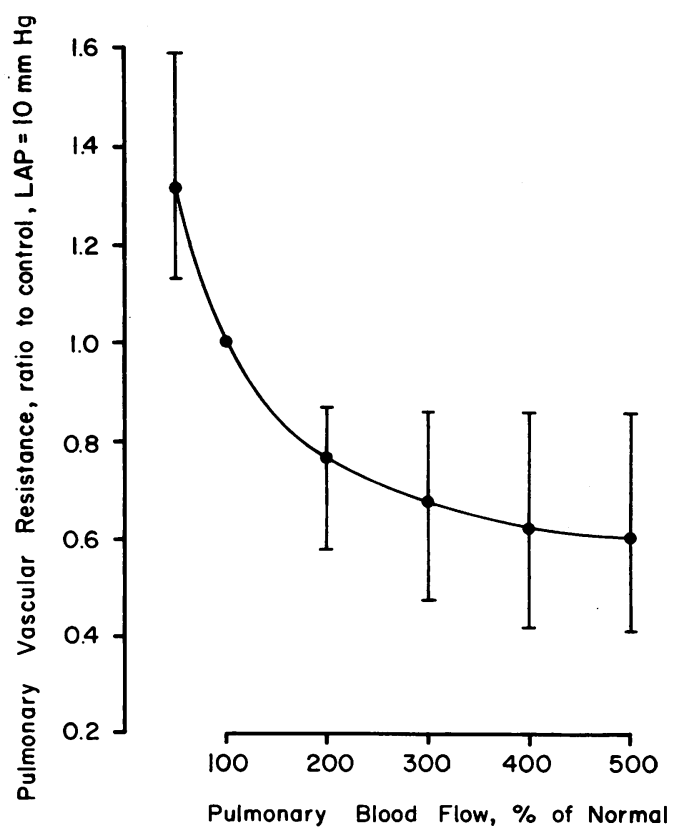

Fig. 6. Average values and ranges of pulmonary VASCULAR RESISTANCES FOR A GIVEN PULMONARY BLOOD FLow. Given for the six animals of group 2 with left atrial pressure constant at $10 \mathrm{~mm} \mathrm{Hg}$. 
TABLE III

in left lower lobe

\begin{tabular}{|c|c|c|c|c|c|c|c|c|c|c|c|c|c|c|c|c|c|}
\hline \multicolumn{5}{|c|}{$350 \%$} & \multicolumn{5}{|c|}{$375 \%$} & \multicolumn{5}{|c|}{$400 \%$} & \multirow[b]{2}{*}{$\begin{array}{c}\text { Final } \\
\text { pH }\end{array}$} & \multirow{2}{*}{$\begin{array}{c}\text { Final } \\
\text { hema- } \\
\text { tocrit }\end{array}$} & \multirow[b]{2}{*}{$\mathrm{SaO}_{2} \uparrow$} \\
\hline PAP & LAP & $\begin{array}{l}\text { PAP } \\
\text { ratio }\end{array}$ & PVR & $\begin{array}{l}\text { PVR } \\
\text { ratio }\end{array}$ & PAP & LAP & $\begin{array}{l}\text { PAP } \\
\text { ratio }\end{array}$ & PVR & $\begin{array}{l}\text { PVR } \\
\text { ratio }\end{array}$ & PAP & LAP & $\begin{array}{l}\text { PAP } \\
\text { ratio }\end{array}$ & PVR & $\begin{array}{l}\text { PVR } \\
\text { ratio }\end{array}$ & & & \\
\hline$m m$ & $\mathrm{Hg}$ & & & & $m m$ & $\mathrm{Hg}$ & & & & $m m$ & $H g$ & & & & & & $\underset{\text { capacity }}{\%}$ \\
\hline 50 & 7.1 & $(1.92) \ddagger$ & $32.7 \ddagger$ & $(0.55) \ddagger$ & & & & & & & & & & & 7.56 & 48 & 100.9 \\
\hline 35 & 10.7 & $(1.83)$ & 29 & $(0.45)$ & 37 & 10.9 & (1.93) & 29 & $(0.45)$ & & & & & & 7.48 & 41 & 106.0 \\
\hline 30 & 5.5 & (1.98) & 15.5 & $(0.54)$ & 31.5 & 7.0 & $(2.10)$ & 14.5 & $(0.50)$ & 33 & 7.8 & $(2.21)$ & 14 & $(0.48)$ & 7.46 & 38 & 88.6 \\
\hline 50 & 8.9 & $(2.28)$ & 23 & $(0.62)$ & 54.5 & 10.4 & (2.48) & 23.1 & $(0.62)$ & 58 & 11.6 & $(2.58) \S$ & 23.28 & $(0.62) \S$ & 7.42 & 42 & 104.0 \\
\hline
\end{tabular}

lobe of the dog lung with blood flows of up to $1 \mathrm{~L}$ per minute. In the studies of Williams there was no tendency of pulmonary vascular resistance to rise above the normal with increasing flow as described by Lategola in the anesthetized closedchest dog (9). Although the study of Williams does not relate left lower lobe pulmonary flow to the size of the animals or to normal pulmonary flow, it is possible that the flows were as high as three to four times normal. Studies by Brofman and associates (13) showed that occlusion of one main pulmonary arterial branch in normal human subjects was invariably associated with an increase in main pulmonary arterial pressure. When

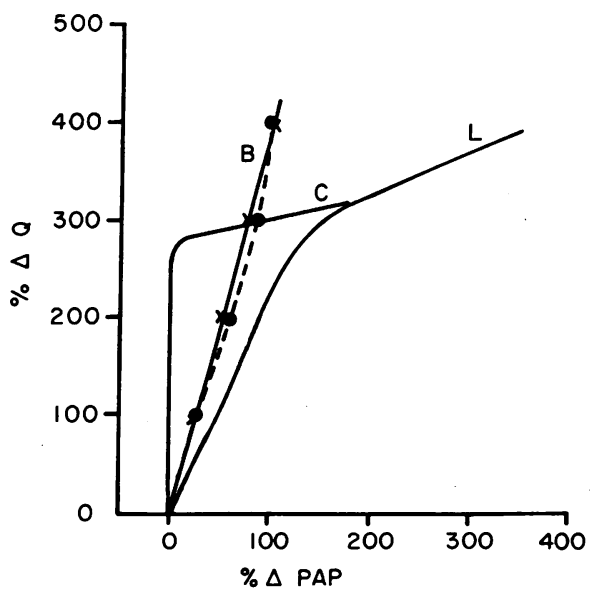

Fig. 7. Pulmonary flow to PREsSURe Relationships AS DETERMINED BY FOUR DIFFERENT INVESTIGATORS. B is the Brofman curve; $\mathrm{C}$ is the Cournand curve; $\mathrm{L}$ is the Lategola curve. The curve employing $X$ 's is from the present experiments with left atrial pressure constant at $10 \mathrm{~mm} \mathrm{Hg}$. $Q=$ pulmonary flow, and $\mathrm{PAP}=$ mean pulmonary arterial pressure. the total cardiac output passed through one lung, the average pressure rose from $17 \mathrm{~mm} \mathrm{Hg}$ to 23 $\mathrm{mm} \mathrm{Hg}$. Occlusions were maintained up to 2 hours. The rise in pulmonary arterial pressure was immediate and sustained at this level throughout the period of occlusion. These workers exercised patients with unilateral balloon occlusion of the pulmonary artery and did not find a striking rise in pulmonary arterial pressure when the pul-

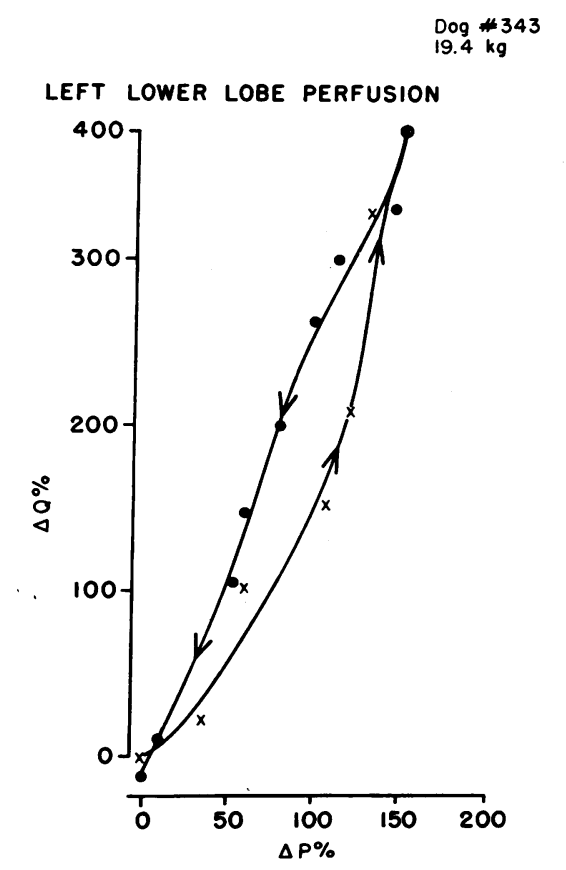

Fig. 8. PRESSURE to FLOW RELATIONSHIPS DURING LEFT LOWER LOBE PERFUSION IN ONE ANIMAL OF GROUP 2 . The $X$ 's indicate pressures (P) obtained as flow was increased; the dots indicate pressure values obtained as flow was decreased. 
TABLE IV

Left lower lobe perfusion during $100 \% \mathrm{O}_{2}$ ventilation

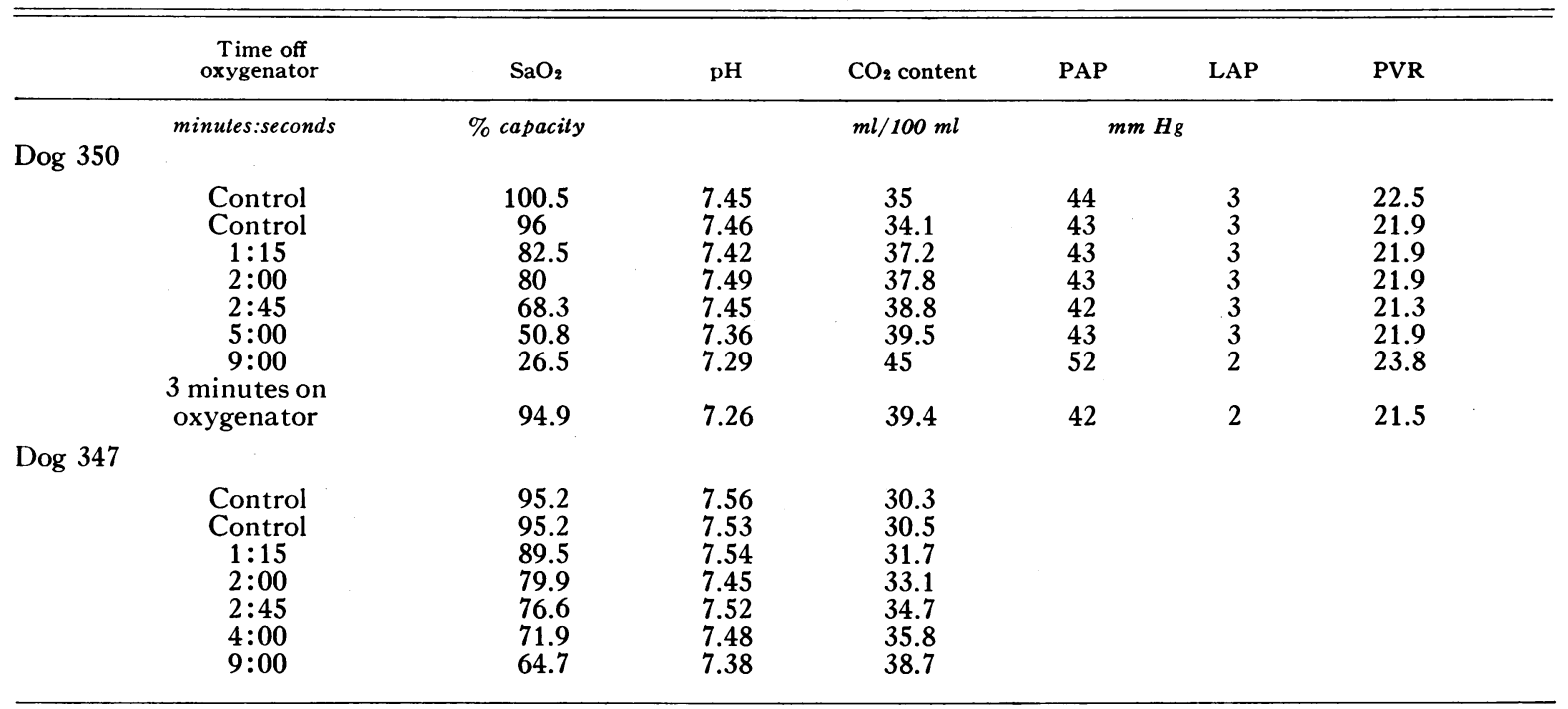

monary blood flow increased two and five-tenths to three times above normal.

It is now necessary to consider the reasons for the differences in the curves that we obtained and those found by Lategola (9). We studied openchest animals during positive pressure respiration; Lategola did not. The use of positive pressure breathing would tend to increase pulmonary vascular resistance over the entire curve, but it should not change the shape of the curve $(13,14)$. When intrapulmonary pressure is raised, there are two mechanisms that may increase pulmonary vascular resistance (14). One is a rise in perivascular pressure for those vessels near the alveoli. The other is longitudinal stretch of blood vessels with greater lung inflation, which may in turn cause vascular narrowing. The effect of a change in alveolar pressure upon pulmonary arterial pressure may be much more profound when pulmonary venous pressure is near or below atmospheric levels (15). Since we found a tendency to lower rather than higher resistances at high levels of pulmonary blood flow, the use of positive pressure breathing would not explain the difference. Left atrial pressure rose as pulmonary flow was increased in our group 1 experiments. Increase of left atrial pressure is known to decrease pulmonary vascular resistance (16). However, a similar but less pronounced decrease in pulmonary vascular resistance was found with increasing flow in our group 2 experiments, in which left atrial pressure was constant. Was there a difference in the state of the nervous system? In our investigation carotid sinus reflexes were found to be intact at the end of the experiments. Many of our studies were carried out under morphine-chloralose anesthesia so that reflex activity should have been preserved. Many studies were made with balloon occlusion and no dissection at the hilum of the lung to damage the nerves around the pulmonary vessels.

The following points must be considered as significant differences in the two investigations. In our work the pulmonary flows were measured directly; those of Lategola (9) were not. The studies made by Lategola at a high percentage increment of pulmonary flow involved the use of two balloon catheters so that only a portion of one lung was being perfused. It is not unlikely that some pulmonary edema occurred, which would have impaired the uptake of oxygen required for the Fick principle. A further possibility is that the great flow through such a small portion of the lung was accompanied by hypoxia, which increased pulmonary vascular resistance above normal. The development of severe hypoxia along with hypercapnia and acidosis in our experiments when one pulmonary lobe only was perfused suggests this possibility. These changes are known to increase pulmonary vascular resistance (17-19). Although 
the pulmonary resistance increase in our dog 350 was only modest, the response of the dog's pulmonary circulation to hypoxia is known to be often delayed or transient (20). Thus the effect of hypoxia and respiratory acidosis might have been greater in Lategola's studies than shown here. Another possibility is that the inflation of the pulmonary arterial balloon in a small pulmonary arterial branch produced a reflex increase in resistance in the remaining lung, thus causing the pressure/flow curve to become convex toward the flow axis. It must be added that the inflection point on this curve at a flow increase of 250 to $300 \%$ described in Lategola's experiments (9) depended upon only two observations out of eight experiments at high flow. With the exception of these two observations, the pulmonary pressure to flow relationship in his study closely resembles that in ours.

Neither our studies in perfused lungs of the dog nor those of Brofman and associates in man (12) demonstrated increasing pulmonary vascular resistance as pulmonary flow increased. Our data demonstrated a linear relationship between pulmonary arterial pressure and flow, especially at higher levels of flow, consistent with the pressure/ flow curve typical of a passive vascular bed (11). The initial rapid decrease of pulmonary vascular resistance as flow was increased from below normal levels is consistent with vasodilation or opening of previously unperfused vessels. The fact that pressure rose less rapidly than flow on the linear portion of the curve can be explained by the reduction in apparent viscosity at higher flows in small vessels (21). Brofman's studies and ours show that any appreciable increase in pulmonary blood flow is attended by some immediate increase of pulmonary arterial pressure. Such changes were regularly observed in these experiments and in the studies reported of exercise and pulmonary arterial pressure in normal supine human subjects by Dexter and associates (6) and by Slonim, Ravin, Balchum, and Dressler (7). Presumably, in time the pulmonary vascular bed adapts itself to increases of flow so that after some months the resting pulmonary arterial pressure is normal after pneumonectomy, provided that the remaining lung is normal.

A number of investigators $(4,5,8)$ have failed to find an increase of pulmonary arterial pressure in normal human subjects during exercise, even when pulmonary blood flow was as much as twice the normal. There are a number of differences between passive increases of pulmonary flow achieved by a mechanical pump or by pulmonary arterial branch occlusion and flow increases produced by exercise. With exercise, a different pressure to flow relationship might result from changes in acid-base balance, autonomic nervous system effects, the release of humoral factors, or changes in the oxygen content of pulmonary arterial blood. The relation between pulmonary arterial blood pressure and pulmonary blood flow in man is of practical significance. Under ordinary circumstances it is unlikely that pulmonary blood flow five times the normal resting value, the maximal value used in these studies, develops during exercise. Mitchell, Sproule, and Chapman (22) studied 15 normal men during treadmill exercise and found that maximal oxygen uptake averaged nine and five-tenths times the resting value. Cardiac outputs at this time had increased four and three-tenths times the control values. Hence, if there were a sharp rise in pulmonary arterial pressure and vascular resistance at a pulmonary blood flow of three to three and one-half times the normal, performance during exercise might be limited by a strain on the right ventricle. The pulmonary arterial pressure/flow curve is of special significance in patients with one lung removed or destroyed by disease; here pulmonary blood flows of four to six times the normal through the remaining lung can be achieved by ordinary daily activity. If the left atrial pressure remains normal, as suggested by studies of left ventricular enddiastolic pressure by Ross, Mason, Bender, and Braunwald (23), such high flows will only approximately double the pulmonary arterial pressure of the normal remaining lung. This degree of pulmonary hypertension is of itself unlikely to limit exercise tolerance of such patients.

\section{Summary}

The relationship between pulmonary arterial pressure and pulmonary blood flow at high flow rates was studied in three groups of dogs. In one group of nine open-chest dogs, constant and equal systemic and pulmonary flow rates were evaluated with the heart arrested. Flow rates above $200 \%$ of normal through one lung were obtained by bal- 
loon occlusion or snare occlusion of the pulmonary artery to the other lung. In a second group of six dogs, similar studies were made during constant left atrial pressure. In a third group of four open-chest animals, pulmonary pressure to flow relationships were studied while the beating heart perfused the left lower lobe only. When left atrial pressure was held constant, pulmonary vascular resistance fell as the flow rate was increased stepwise from 50 to $500 \%$ of normal. At $200 \%$ of normal flow, pulmonary arterial pressure increase was $28 \%$ above control ; at $300 \%$ of normal flow, the mean pressure increase was $53 \%$; at $400 \%$ of normal flow, the mean pressure increase was $78 \%$; and at $500 \%$ of normal flow, the mean pressure increase was $104 \%$. Similar results were obtained in the animals of groups 1 and 3 . In no animal did the pulmonary vascular resistance increase with increasing flow within the flow range studied, although the rate of decrease in resistance fell with increasing flow rates. These studies do not support the concept that pulmonary arterial pressure increases sharply when pulmonary flow rises to approximately 350 to $400 \%$ of normal.

\section{References}

1. Dotter, C. T., and D. S. Lukas. Acute cor pulmonale. An experimental study utilizing a special cardiac catheter. Amer. J. Physiol. 1951, 164, 254.

2. Sloan, H., J. D. Morris, M. Figley, and R. Lee. Temporary unilateral occlusion of the pulmonary artery in the preoperative evaluation of thoracic patients. A preliminary report. J. thorac. Surg. 1955, 30, 591.

3. Brofman, B. L. Experimental unilateral pulmonary artery occlusion in humans (abstract). Circulat. Res. 1954, 2, 285.

4. Hickam, J. B., and W. H. Cargill. Effect of exercise on cardiac output and pulmonary arterial pressure in normal persons and in patients with cardiovascular disease and pulmonary emphysema. J. clin. Invest. 1948, 27, 10.

5. Riley, R. L., A Himmelstein, H. L. Motley, H. M. Weiner, and A. Cournand. Studies of the pulmonary circulation at rest and during exercise in normal individuals and in pataients with chronic pulmonary disease. Amer. J. Physiol. 1948, 152, 372.

6. Dexter, L., J. L. Whittenberger, F. W. Haynes, W. T. Goodale, R. Gorlin, and C. G. Sawyer. Effect of exercise on circulatory dynamics of normal individuals. J. appl. Physiol. 1951, 3, 439.

7. Slonim, N. B., A. Ravin, O. J. Balchum, and S. H. Dressler. The effect of mild exercise in the supine position on the pulmonary arterial pressure of five normal human subjects. J. clin. Invest. 1954, 33, 1022.

8. Cournand, A., R. L. Riley, A. Himmelstein, and R. Austrian. Pulmonary circulation and alveolar ventilation-perfusion relationships after pneumonectomy. J. thorac. Surg. 1950, 19, 80.

9. Lategola, M. T. Pressure-flow relationships in the dog lung during acute, subtotal pulmonary vascular occlusion. Amer. J. Physiol. 1958, 192, 613.

10. Fowler, N. O., and J. C. Holmes. Pulmonary pressor action of $l$-norepinephrine and angiotensin. Amer. Heart J. 1965, 70, 66.

11. Green, H. D., and C. E. Rapela. Blood flow in passive vascular beds. Circulat. Res. 1964, 15, (suppl. I), 11 .

12. Brofman, B. L., B. L. Charms, P. M. Kohn, J. Elder, R. Newman, and M. Rizika. Unilateral pulmonary artery occlusion in man. Control studies. J. thorac. Surg. 1957, 34, 206.

13. Williams, M. H., Jr. Relationships between pulmonary artery pressure and blood flow in the dog lung. Amer. J. Physiol. 1954, 179, 243.

14. Roos, A., L. J. Thomas, Jr., E. L. Nagel, and D. C. Prommas. Pulmonary vascular resistance as determined by lung inflation and vascular pressures. J. appl. Physiol. 1961, 16, 77.

15. West, J. B., and C. T. Dollery. Distribution of blood flow and the pressure-flow relations of the whole lung. J. appl. Physiol. 1965, 20, 175.

16. Borst, H. G., M. McGregor, J. L. Whittenberger, and E. Berglund. Influence of pulmonary arterial and left atrial pressures on pulmonary vascular resistance. Circulat. Res. 1956, 4, 393.

17. Motley, H. L., A. Cournand, L. Werko, A. Himmelstein, and D. Dresdale. The influence of short periods of induced acute anoxia upon pulmonary artery pressures in man. Amer. J. Physiol. 1947, 150, 315.

18. Bergofsky, E. H., D. E. Lehr, M. A. Tuller, M. J. Rigatto, and A. P. Fishman. The effects of acute alkalosis and acidosis on the pulmonary circulation. Ann. N. Y. Acad. Sci. 1961, 92, 627.

19. Enson, Y., C. Giuntini, M. L. Lewis, T. Q. Morris, M. I. Ferrer, and R. M. Harvey. The influence of hydrogen ion concentration and hypoxia on the pulmonary circulation. J. clin. Invest. 1964, 43, 1146.

20. Borst, H. G., J. L. Whittenberger, E. Berglund, and M. McGregor. Effects of unilateral hypoxia and hypercapnia on pulmonary blood flow distribution in the dog. Amer. J. Physiol. 1957, 191, 446.

21. Fåhraeus, R., and T. Lindqvist. The viscosity of the blood in narrow capillary tubes. Amer. J. Physiol. 1931, 96, 562.

22. Mitchell, J. H., B. J. Sproule, and C. B. Chapman. The physiological meaning of the maximal oxygen intake test. J. clin. Invest. 1958, 37, 538.

23. Ross, J., Jr., D. T. Mason, H. W. Bender, and E. Braunwald. Assessment of left ventricular function in man. Circulation 1963, 28, 793. 